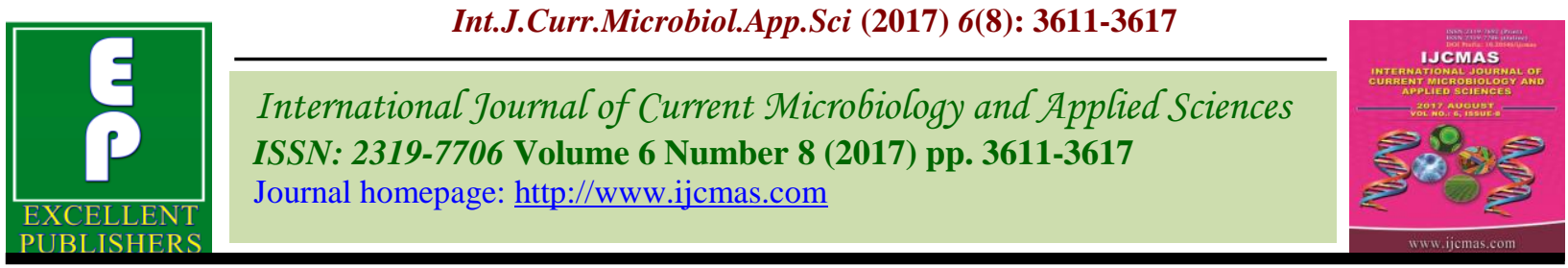

Original Research Article

https://doi.org/10.20546/ijcmas.2017.608.434

\title{
A Study of Bacteriology of Burn Wound Infections
}

\author{
Anushka V. Devnikar* and S. S. Solabannavar \\ Department of Microbiology, S. Nijalingappa Medical College, \\ Navanagar, Bagalkot - 587102, Karnataka, India \\ *Corresponding author
}

\begin{tabular}{|c|c|}
\hline \multicolumn{2}{|r|}{ A B S T R A C T } \\
\hline & \multirow{5}{*}{$\begin{array}{l}\text { Burn wounds are one of the most common and devastating forms of trauma. Infections are } \\
\text { an important cause of morbidity and mortality in burn patients. It has been estimated that } \\
75 \% \text { of all deaths following burns are due to infections. To study the bacteriological } \\
\text { spectrum of burn wound infections, their antimicrobial sensitivity pattern and time related } \\
\text { changes in microbial colonization. The study was conducted in microbiology department } \\
\text { and burn care unit in a tertiary care centre. Samples were collected weekly from patients } \\
\text { admitted with burn injuries. Relevant patient information was collected in a proforma. } \\
\text { Sample processing and antibiotic sensitivity testing was performed according to standard } \\
\text { laboratory procedures. A total of } 147 \text { microorganisms were isolated from } 105 \text { patients with } \\
\text { burn wounds admitted in our hospital. The most frequent isolates was Pseudomonas } \\
\text { aeruginosa, Staphylococcus aureus, coagulase negative Staphylococcus, Klebsiella } \\
\text { pneumoniae, Escherichia coli, Proteus mirabilis and Enterococcus species. Time related } \\
\text { changes in burn wound colonization showed an initial predominance of Gram positive } \\
\text { cocci in the first week following admission. In the next week, gram negative bacilli began } \\
\text { to predominate. Antimicrobial sensitivity testing showed Imipenem and vancomycin, } \\
\text { linezolid were most effective against the Gram negative and Gram positive isolates } \\
\text { respectively. It is crucial for every burn unit to determine the specific pattern of burn } \\
\text { wound colonization, the time related changes in the microbial flora and the antimicrobial } \\
\text { resistance pattern. This will enable early treatment of imminent septic episodes with proper } \\
\text { empirical systemic antibiotics thus improving overall infection related morbidity and } \\
\text { mortality. }\end{array}$} \\
\hline Keywords & \\
\hline Article Info & \\
\hline $\begin{array}{l}\text { Accepted: } \\
\text { 27 June } 2017 \\
\text { Available Online: } \\
\text { 10 August } 2017\end{array}$ & \\
\hline & \\
\hline
\end{tabular}

\section{Introduction}

Burns are one of the most devastating forms of trauma. Worldwide around 265,000 deaths occur per year due to burns ${ }^{1}$. The survival rate for burn patients has improved substantially in the past few decades due to advances in modern medical care in specialized burn centers. Now infections are becoming a leading cause of mortality and currently $75 \%$ of all deaths are related to sepsis from burn wound infection or other complications due to infections $^{2}$.

Burn wounds are more prone to infection due to the destruction of skin barrier and concomitant suppression of immune responses. Also, the burn wound surface provides a favourable niche for microbial colonization and proliferation. A vascularity 
of the eschar causes impaired migration of host immune cells and restricts delivery of systematic antimicrobial agents ${ }^{3}$. If this colonization is not controlled promptly, it progresses to invasion and gives rise to bacteraemia and sepsis ${ }^{4}$. The risk of infection is influenced by the extent and depth of the injury, age of the patients, the colonizing microorganism and its invasive potential. ${ }^{5}$

The organisms implicated in burn wound infections include Pseudomonas aeruginosa, Staphylococcus species, Acinetobacter species, Proteus species, Klebsiella species, etc. These pathogens vary a cross different hospitals. Additionally, the composition of bacteria infecting burn wounds changes depending on the duration of burns. Furthermore, emerging bacterial antimicrobial resistance poses a serious therapeutic challenge $^{6,7}$.

Therefore, the present study was undertaken to determine bacteriological spectrum of burn wound infections in our burn care unit and their anti-microbial sensitivity pattern and also to note the time related changes of the pathogens infecting the burn wound.

\section{Materials and Methods}

The study was conducted in the department of Microbiology and the burn care unit for a period of 2 years from April 2010 to March 2012 in HSK hospital and Research Centre, Bagalkot. Ethical clearance was obtained from institutional ethical committee. All patients admitted to the burn care unit were included in the study. Patients with burns treated on an out-patient basis were excluded. After taking informed consent from the patient, relevant clinical history was recorded in a pre-designed proforma.

Two swabs were collected from the burn wound on admission and every week thereafter until discharge or death of the patient ${ }^{8}$. The swabs were transported immediately to the microbiology laboratory immediately. One swab was used for Gram staining and the other swab was used for culture. The samples were inoculated onto chocolate agar, blood agar and MacConkey agar. The isolates were identified as per standard microbiological techniques ${ }^{9}$.

The antimicrobial susceptibility test of isolates was performed on Muller Hinton agar by Kirby Bauer's disc diffusion method using standard guidelines and interpretive criteria ${ }^{10}$.

\section{Results and Discussion}

A total of one hundred and five patients admitted in the burn unit in our hospital over a period of 2 years were studied. Overall, the most common cause for burn wounds was burns due to heat $(80 \%)$ followed by scalds $(14.3 \%)$, electric burns $(3.8 \%)$ and chemical burns (1.9\%).

Among children scalds (55.6\%) was the most common cause. The overall mortality rate was $40.95 \%$. In burn wounds with TBSA more than $60 \%$, the mortality rate was $73.68 \%$.

The duration of hospitalization ranged from 1 day to 22 days with mean duration being 5.76 +4.56 days.Age ranged from 6 months to 80 years. Maximum incidence was noted during the second and third decades (55.2\%).Burn wounds were more in females $(65.7 \%)$ than in males (34.3\%).

From the 105 patients, a total of 135 samples were taken and 147 organisms were isolated.

The overall isolation rate was $83.7 \%$. Solitary isolates $(61.48 \%)$ were more common than multiple isolates (38.52\%). Overall, Pseudomonas aeruginosa $(37.41 \%)$ was the most common isolate (Figure 1). 
In the first week following burn injury, Gram positive cocci were predominant whereas later, the frequency of isolation of Gram negative organisms increased and that of Gram positive organisms decreased (Figure 2).

Antibiotic sensitivity testing showed vancomycin and linezolid (100\%) as most effective antimicrobials against Gram positive organisms. Least sensitive antimicrobial against Gram positive isolates was penicillin (24.29\%).We found $33.33 \%$ Methicillin Resistant Staphylococcus aureusand $21.21 \%$ methicillin resistant CONS. Imipenem $(98.7 \%)$ was the most effective drug against Gram negative isolates. Least effective drug against Gram negative isolates was cotrimoxazole (Tables 1 and 2).

A burn is an injury to the skin or other organic tissue primary caused by heat or due to radiation, electricity, friction or contact with chemicals. Infection of burn wound is the most common complication and remains a major cause of morbidity and mortality. In our study, we found that burns due to heat $(80 \%)$ were seen most commonly. It was followed by burns due to scalds seen in $14.3 \%$ of the cases. Most of the scalds injuries were seen in children below 10 years of age. Scalds have unanimously been found to be the predominant form of burns among children ${ }^{11}$. As age increased, frequency of scalds decreased and flame burns increased. More than half of the patients $(55.2 \%)$ were in the age group of 20 to 40 years and incidence was more in females. High incidence of burns in females is probably due to hazards of working in the kitchen with an open flame or fire.

Prevalence of Pseudomonas species in the burn wards, the predominant organism in our study, maybe because the organism thrives in a moist environment ${ }^{12}$.It has been found to contaminate the floors, bed rails, and sinks of hospitals, and even the hands of nurses. Beside transmission through fomites and vectors, bacterial flora can be carried into a hospital by the patient and can be an important source of infection for the same individual after injury ${ }^{13,14}$. The situation is further complicated by the fact that $\mathrm{P}$. aeruginosa is intrinsically resistant to some commonly used disinfectants, antiseptics and antibiotics $^{14,15}$.

Table.1 Antibiotic sensitivity testing of gram positive isolates

\begin{tabular}{|c|c|c|c|}
\hline & S. aureus (36) & CONS (33) & Enterococcus sp. (1) \\
\hline $\mathbf{P}$ & $6(17)$ & $11(33)$ & $0(0)$ \\
\hline $\mathbf{E}$ & $22(61)$ & $15(46)$ & $0(0)$ \\
\hline CD & $28(78)$ & $25(76)$ & $0(0)$ \\
\hline CIP & $17(47)$ & $16(49)$ & $0(0)$ \\
\hline DO & $26(72)$ & $25(76)$ & NT \\
\hline CTX & $21(58)$ & $22(67)$ & $1(100)$ \\
\hline $\mathbf{C X}$ & $24(67)$ & $26(79)$ & NT \\
\hline COT & $21(58)$ & $17(52)$ & $0(0)$ \\
\hline GEN* & $20(56)$ & $20(61)$ & $1(100)$ \\
\hline $\mathbf{L Z}$ & $36(100)$ & $33(100)$ & $1(100)$ \\
\hline $\mathbf{V A}$ & $36(100)$ & $33(100)$ & $1(100)$ \\
\hline \multicolumn{4}{|c|}{$\begin{array}{l}\text { NT - not tested } \\
\text { * high level gentamicin was used for Enterococcus species } \\
\text { P-penicillin, E-erythromycin, CD-clindamycin, CIP-ciprofloxacin } \\
\text { DO-doxycycline, CTX-cefotaxime, CX-cefoxitin, COT-sulfamethoxazole-trimethoprim, } \\
\text { GEN-gentamicin, LZ-linezolid, VA-vancomycin }\end{array}$} \\
\hline
\end{tabular}


Table.2 Antibiotic sensitivity testing of gram negative isolates

\begin{tabular}{|c|c|c|c|c|c|}
\hline & $\begin{array}{c}\text { P. aeruginosa } \\
(55)\end{array}$ & $\begin{array}{c}\text { K. pneumoniae } \\
(11)\end{array}$ & $\begin{array}{c}\text { E. coli } \\
(6)\end{array}$ & $\begin{array}{c}\text { P. mirabilis } \\
\text { (3) }\end{array}$ & $\begin{array}{c}\text { C. freundii } \\
\text { (2) }\end{array}$ \\
\hline CTX & NT & $0(0)$ & $2(33.3)$ & $2(67)$ & $1(50)$ \\
\hline CTR & NT & $4(36)$ & $3(50)$ & $2(67)$ & $0(0)$ \\
\hline $\mathrm{CAZ}$ & $17(31)$ & $5(46)$ & $3(50)$ & $2(67)$ & $2(100)$ \\
\hline CPM & $15(27)$ & $4(36)$ & $2(33.3)$ & $1(33)$ & $0(0)$ \\
\hline PI & $28(51)$ & $1(9)$ & $3(50)$ & $2(67)$ & $0(0)$ \\
\hline PIT & $50(91)$ & $10(91)$ & $6(100)$ & $3(100)$ & $2(100)$ \\
\hline AK & $36(66)$ & $2(18)$ & $3(50)$ & $3(100)$ & $0(0)$ \\
\hline GEN & $33(60)$ & $0(0)$ & $3(50)$ & $2(67)$ & $0(0)$ \\
\hline COT & NT & $0(0)$ & $1(16.7)$ & $0(0)$ & $0(0)$ \\
\hline CIP & $29(53)$ & $2(18)$ & $2(33.3)$ & $2(67)$ & $1(50)$ \\
\hline IPM & $54(98)$ & $11(100)$ & $6(100)$ & $3(100)$ & $2(100)$ \\
\hline AT & $42(76)$ & NT & NT & NT & NT \\
\hline TI & $29(53)$ & NT & NT & NT & NT \\
\hline \multicolumn{6}{|c|}{$\begin{array}{l}\text { *NT- Not tested } \\
\text { CTX-cefotaxime, CTR-ceftriaxone, CAZ-ceftazidime, CPM-cefepime, PI-Piperacillin, } \\
\text { PIT-piperacillin-tazobactam, AK-amikacin, GEN-gentamicin, COT-sulfamethoxazole-trimethoprim } \\
\text { CIP-ciprofloxacin, IPM-imipenem, AT-aztreonam, TI-ticarcillin }\end{array}$} \\
\hline
\end{tabular}

Fig.1 Distribution of isolates

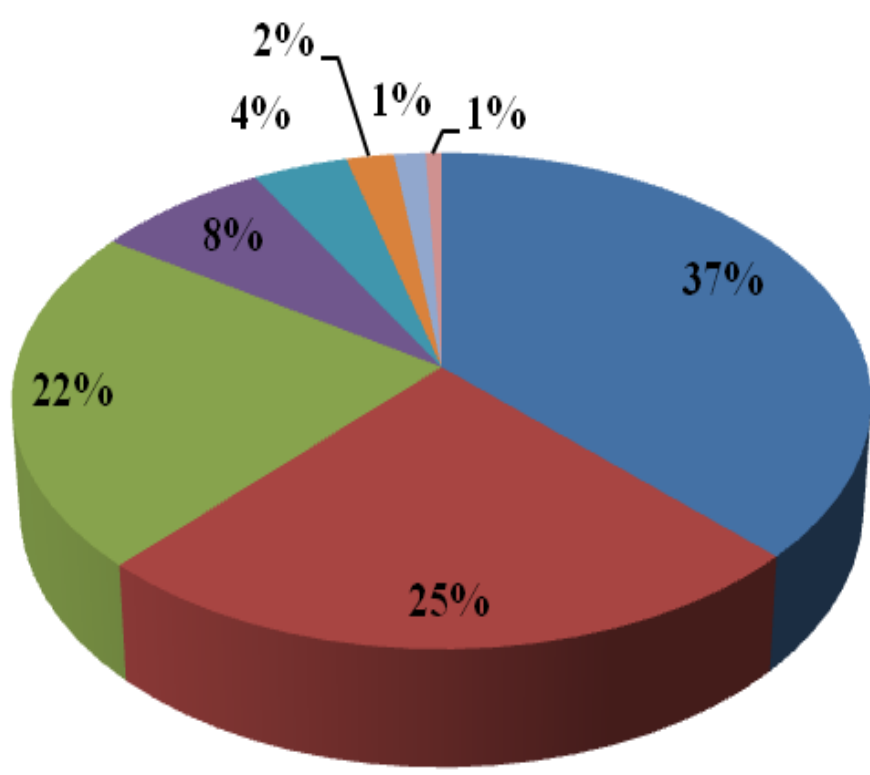

Pseudomonas aeruginosa

- Staphylococcus aureus

CONS

- Klebsiella pneumoniae

Escherichia coli

- Proteus mirabilis

Citrobacter freundii

Enterococcus species 
Fig.2 Time related changes of the isolates

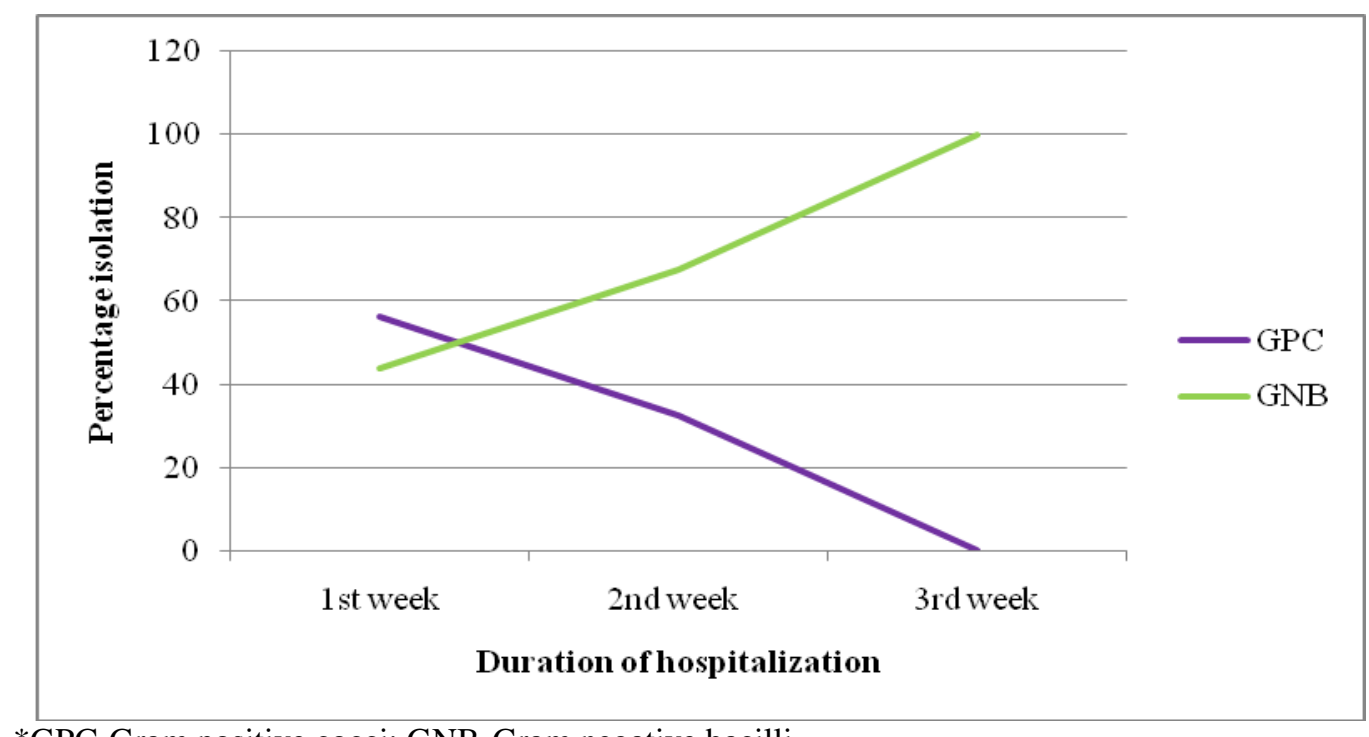

*GPC-Gram positive cocci; GNB-Gram negative bacilli

The second common isolate was Staphylococcus aureus. This is in contrast, however to some other studies particularly from developed countries which report $S$. aureus as the most predominant organism in burn patients 16, 17. Staphylococcus aureus was the predominant cause of burn wound infection in the pre-antibiotic era and remains an important pathogen at present, especially due to the emergence of Methicillin resistant Staphylococcus aureus (MRSA). In our study, prevalence of MRSA was $33.3 \%$. Other studies have reported prevalence ranging from 6.8 to $23.5 \%$.

In our study, coagulase negative Staphylococci (CONS) were recovered at a frequency of $22.44 \%$. Of these, $87.88 \%$ were isolated in the first week, followed by $12.12 \%$ in the second week and none in the third week. In view of the immunocompromised status of the burned patients, it has been consistently stressed that coagulase negative Staphylococci should be considered a significant pathogen ${ }^{19}$.

We were able to corroborate the variation in the composition of bacterial flora depending on the duration of burns. The organisms infecting the burn wound changed over time in an individual patient ${ }^{20}$. Initially, the wound surface was predominantly colonized by Gram positive bacteria such as Staphylococcus aureus and Coagulase negative Staphylococci, probably derived from the adjacent skin surface. Subsequently by $5^{\text {th }}$ to $7^{\text {th }}$ day, there was increase in colonization by gram negative microbes possibly derived from the from the hospital environment or from the host's normal flora of the respiratory tract or gastrointestinal tract 8 . This was accompanied by a decrease in incidence of gram positive organisms.

Earlier studies of antibiotic sensitivity among burn wound isolates have shown a gradual increase in resistance over time. Studies have shown that most of the organisms causing infection in burn patients are highly resistant to routinely used antibiotics 21,22 .

The resulting antibiogram gives some cause for concern because the predominant bacterial isolates are relatively resistant to the commonly available, more economical antimicrobials. Hospitals are an important 
breeding ground for the development and spread of antibiotic resistance. This is the consequence of exposure to heavy antibiotic use, high density of patient population in frequent contact with health care workers and patient attendants and lack of adherence to infection control practices.

We were unable to collect simultaneous blood cultures to correlate the invasiveness of the burn wound infection. This was the limitation of this study.

In conclusion, our results have provided useful information regarding the pattern of burn wound microbial colonization, the dominant flora and antimicrobial resistance in our burn unit. They will aid the formulation of effective guidelines for early and appropriate therapy, thus improving overall infection related morbidity and mortality.

However, the spectrum of pathogens causing burn wound infections is ever changing. Moreover, antimicrobial resistance is continually on the rise. Keeping this in mind, it is desirable to carry out periodic reviews of the bacterial flora of burn wounds in all centers so that preventive strategies can be modified as necessary.

\section{References}

Agnihotri, N., Gupta V, Joshi RM. Aerobic bacterial isolates from burn wound infections and their antibiograms - a five year study. Burns 2004;30:241-243

Bain, J., Lal S, Baghel VS, Yedalwar V, Gupta R, Singh AK. Decadorial of a burn center in Central India. J Nat $\mathrm{Si}$ Biol Med 2014; 5:116-22

Bairy, I., Shivananda PG. Aerobic bacterial flora of burn wound infection. Ind $\mathbf{J}$ Surg 1997; 59:215-218

Bhama, S., Rajan R, Theodore RJ. A study on bacterial profile of burn wound infections. J AcadClinMicrobiol 2013; 15:54-58

Chamania, S., Hemvani N, Joshi S. Burn wound infection: Current problem and unmet needs. Indian J Burns 2012; 20:18-22

Church, D., Elsayed S, Reid O, Winston B, Lindsay R. Burn wound infections. ClinMicrobiol Rev 2006; 19(2):403-434

CLSI. Performance standards for antimicrobial susceptibility testing; Eighteenth Informational Supplement. CLSI document M100-S18. Wayne, PA: Clinical and Laboratory Standards Institute; 2008

Collee, G., Duguid P, Fraser G, Marian P. Mackey and McCartney's Practical medical microbiology. 14th Ed. Delhi: Churchill Livingstone Publishers; 2007

El Morsi HAR. The diagnosis and treatment of infection in the burn patient. Annals of the MBC 1990; 3(1):1-5

Guggenheim, M., Zbinden R, Handschin AE, Gohritz A, Altintas MA, Giovanoli P. Changes in bacterial isolates from burn wounds and their antibiograms: A 20 year study (1986-2005). Burns 2009;35:553-560

Imran, M., Faheem M, Aslam V, Hakeem A, Rehman I, Shah A. Wound infections and culture sensitivity pattern in paediatric burn patients. JPMI 2009;23(4):304-308

Japoni, A., Farshad S, Alborzi A. Pseudomonas aeruginosa: Burn infection, treatment and antibacterial resistance. Iranian Red Crescent Medical Journal 2009;11:244-53

Kumar, C.A., Mathur M, Salunke P, Baweja $\mathrm{S}$. Time related changes of microbial flora in burns unit at a tertiary care hospital. Bombay Hospital Journal 2010; 52:205-09

Mahon, C.R., Lehman DC, Manuselis G. Textbook of diagnostic microbiology. $3^{\text {rd }}$ Ed. India Elsevier; 2007 
Mandell, G.L., Bennett JE, Dolin R. Mandell, Douglas and Bennett's principles and practice of infectious diseases. 7th Ed. USA: Churchill Livingstone Elsevier; 2010

Murray, P.R., Baron EJ, Jorgensen JH, Landry ML, Pfaller MA. Manual of Clinical Microbiology. $9^{\text {th }}$ Ed. China: American Society for Microbiology Press; 2007

Nasser, S., Mabrouk A, Maher A. Colonization of burn wounds in Ains Shams University burn unit. Burns 2003;29:229-233

Rafla, K., Tredget EE. Infection control in the burn unit. Burns 2011;37:5-15

Rajput, A., Singh KP, Kumar V, Sexena R, Singh RK. Antibacterial resistance pattern of aerobic bacteria isolates from burn patients in tertiary care hospital. Biomed Res 2008; 19(1):1-4

Sharma, M., Taneja N. Burns, antimicrobial resistance and infection control. Indian J Med Res 2007; 126:505-507

Taneja, N., Chari PS, Singh M, Singh G, Biswal M, Sharma M. Evolution of bacterial flora in burn wounds: key role of environmental disinfection in control of infection. Int $\mathrm{J}$ Burns Trauma 2013;3:102-7

WHO fact sheet (Internet): Burns World Health Organization Sept 2016. Available from http://www.who.int/mediacentre/factshe ets/fs365/en/

\section{How to cite this article:}

Anushka V. Devnikar and Solabannavar, S. S. 2017. A Study of Bacteriology of Burn Wound Infections. Int.J.Curr.Microbiol.App.Sci. 6(8): 3611-3617. doi: https://doi.org/10.20546/ijcmas.2017.608.434 